\title{
Analysis and Optimisation of Ride Vibration of a Heavy-Duty Truck Based on a Vertical-Pitch-Roll Driver-Vehicle Coupled Dynamic Model
}

\author{
Peng Guo $\mathbb{D}^{1},{ }^{1}$ Jiewei Lin $\mathbb{D},{ }^{2}$ Zefeng Lin $\mathbb{D},{ }^{2}$ Jinlu Li $\mathbb{D},{ }^{2}$ Chi Liu $\mathbb{D},{ }^{3}$ and Tao Zhang $\mathbb{D}^{1}$ \\ ${ }^{1}$ Tianjin Key Laboratory for Advanced Mechatronic System Design and Intelligent Control, School of Mechanical Engineering, \\ Tianjin University of Technology, Tianjin 300384, China \\ ${ }^{2}$ State Key Laboratory of Engines, School of Mechanical Engineering, Tianjin University, Tianjin 300350, China \\ ${ }^{3}$ Institute of Sound and Vibration Research, University of Southampton, 1 BJ, Southampton SO17, UK
}

Correspondence should be addressed to Chi Liu; liuchi0511@gmail.com and Tao Zhang; zhangtaojx@email.tjut.edu.cn

Received 11 October 2020; Revised 9 February 2021; Accepted 20 February 2021; Published 26 February 2021

Academic Editor: Manuel Aenlle Lopez

Copyright (c) 2021 Peng Guo et al. This is an open access article distributed under the Creative Commons Attribution License, which permits unrestricted use, distribution, and reproduction in any medium, provided the original work is properly cited.

\begin{abstract}
The ride comfort and the cargo safety are of great importance in the vibration design of heavy-duty vehicle. Traditional ride comfort design method based on the response of components of vehicles or interaction between human and seat overlooks the most direct criterion, the response of occupants, which makes the optimisation not targeted enough. It will be better to conduct the ride comfort design with the biodynamic response of driver. To this end, a 17-degrees-of-freedom (DOFs) vertical-pitch-roll vehicle dynamic model of a three-axle heavy-duty truck coupled with a 7 DOFs human model is developed. The ride comfort of human body under the vertical, the pitch, and the roll vibrations can be evaluated with the weighted root-mean-square (r.m.s.) acceleration of the driver in multiple directions. The flexibilities of chassis and carriage are also considered to improve the accuracy of the prediction of the ride comfort and to constrain the mounting optimisation of cab and carriage. After validation, the sensitivity analysis of the mounting system, the suspensions, and arrangement of sprung masses is carried out and significant factors to ride vibration are identified. The optimal combination of design parameters is obtained with the objective of minimizing the vibration of the driver and carriage simultaneously. The optimisation result shows that the weighted driver vibration is reduced by $27.9 \%$ and the carriage vibration is reduced by $31.8 \%$ at various speeds.
\end{abstract}

\section{Introduction}

As the requirements for the ride comfort performance of vehicles increase, the human factor to the vibration design is attracting more and more attention especially for a longdistance transport [1]. Among various types of ride vibration, the rotational motions, that is, the pitch and roll motions, affect the comfort sensation of driver and passengers in an even greater manner than the vertical vibration. Apart from the highway, the heavy-duty truck also travels on rough roads connecting the highway and the destination, which means the cargo safety also matters and needs compromise in the vehicle design [2].

Vehicle is a highly coupled dynamic system consisted of subsystems and components with different levels of mass and size. Dynamic simulation is considered as an effective approach in vibration design of vehicles. Abdelkareem and $\mathrm{Xu}$ [3] conducted a bounce and pitch simulation of a half suspension of a heavy truck with 6 DOFs and performed vehicle-level simulations using a 23 -degree-of-freedom full truck semitrailer mathematical model with random road surface model [4]. It was also illustrated that the loading condition had considerable effect on vibration modes of vehicle, and the ride performance could be adjusted through the design of seat suspension [5]. From the systematic point of view, some subsystems can be integrated as a lumped mass but some should be considered as a rigid body with shape, continuous body with continuous mass, and flexible distribution or other models. For a heavy-duty vehicle, the chassis should be a flexible body in the dynamic 
simulation considering its vibration modes greatly affect the vibration transmission between the sprung and unsprung masses [6]. Reference [7] built a multibody dynamic model of a tractor-semitrailer with the flexible cab and chassis. The rigid-flexible coupled model shows good performance of prediction of the ride quality. Reference [8] also showed the flexible-rigid combined dynamic model could represent the rigid motion and the complex shaped deformation simultaneously. An appropriate consideration of subsystem flexibilities of the vehicle helped the ride simulation in both precision and efficiency $[9,10]$. Among all the subsystems, the flexibility of the chassis is of the greatest importance due to its low resonance frequency and large deformation when the sprung masses and their elastic connections are working supported vibration system. Taking the design of the powertrain mounts as an example, the chassis of the heavyduty truck should be considered as a flexible part to constrain the mounting positions during the truck modelling [11]. In the dynamic simulation, the flexible chassis is always incorporated as a Reyleigh beam, which shows good accuracy and efficiency [12].

In most vehicle-level dynamic studies, the ride vibration is evaluated indirectly through the vibrations of the cab floor, the seat rail, or the interactions between human and seat such as seat surface or backrest [13-16]. The actual dynamic behaviours of the occupants are not deeply considered. This reduces the model complexity but ignores the effects of dynamic response of the human body on the ride sensation, especially for those resonant responses that may cause great discomfort $[17,18]$. Taking the driver, seat, and cab as one inseparable system, a 4 DOF model was developed to simulate the ride vibration under measured excitations from cab mounts [19]. A driver-seat-cab model considered the interaction caused by seat suspension was developed to represent the vertical vibration of the driver. Limited by the dimensions of the models, only the vertical accelerations of the quarter car and the driver were described. Reference [20] developed a simple 3 DOFs model to study the drivercushion-car dynamics, and [21] presented a passengers-bus coupled model with a 2 DOFs human model and a 3 DOFs bus model to evaluate the ride comfort of passengers as the bus travelled on different roads at different speeds. It was shown that a passenger-vehicle model was superior when taking the response of occupants directly into optimisation to the traditional ride comfort design method with the vibration of vehicle components.

Most present studies took the vertical vibration as the prior ride index ignoring rotational vibrations that matter in a more considerable extent. It has been proved that a lowamplitude rotational vibration leads to equivalent discomfort caused by a high-amplitude vertical vibration [22, 23]. To consider the rotational vibration, the present driver-seatvehicle model needs expansion in rotational DOFs. Under this consideration, a seated human model considering vertical and pitch motions at the same time would help understanding the complex ride comfort caused by transportation vibration.

In this paper, a coupled driver-vehicle dynamic model in vertical-roll-pitch directions is developed to comprehensively analyse the ride comfort in translational and rotational directions. The first two orders of vibration mode of the chassis are considered to simulate the vibration transmission from unsprang mass to the cab and carriage precisely. After the model validation, the effects of design variables on the ride vibrations are discussed and the sensitivities of them are identified. With a surrogate model of ride prediction, the driver comfort and the acceleration r.m.s. of the carriage are optimised together under various travelling speeds.

\section{Dynamic Models}

2.1. Vehicle Model. The dynamic model of the three-axle heavy-duty commercial vehicle consists of the cab, the carriage, the chassis, the suspensions and mounts, the axles, and the tires. The cab and the carriage are supported on the chassis by elastic mounts, and the axles are connected to the chassis with suspensions. All suspensions and elastic mounts are modelled with paralleled springs and dampers with equivalent stiffness and damping coefficients. The schematic of the vehicle model is shown in Figure 1.

The vehicle is modelled as a left-right symmetric structure according to the longitudinal axis. The left and right suspensions and mounts are identical, but the left and right tracks are different. So, the axles, the chassis, the cab, and the carriage still can vibrate rotationally around the longitudinal axis.

In total, the vehicle dynamic model has 15 DOFs including the vertical, the pitch, and the roll motions of the $\mathrm{cab}$, the carriage, and the chassis, the vertical and the roll motions of the front, and the middle and the rear axles.

2.2. Driver Model. A 7-DOF human biodynamic model [24] is employed to study the dynamic responses of the buttock and thorax of the driver. Seen in Figure 2, the up-right seated human model consists of the thigh, the pelvis, three lower lumbar spinal levels (L3, L4, and L5), the viscera, the upper body from head to L2, and the rotational joints with stiffness and damping properties between them. The thigh and the viscera are assumed to move only in the vertical direction. The remaining parts of the model achieve the bending movements of spine thorough the rotational motion around their joints alone; that is, there is no translational degrees of freedom given to these segments. The seated human body is connected to the seat by spring-damper parallels and the seat is connected to the cab floor in the same way.

2.3. Chassis Model. The chassis of the heavy-duty vehicle is the most flexible substructure whose vibration modes may have significant effect on the response of the superstructures of vehicle. A finite element (FE) model of the chassis with 750525 elements and 1460365 nodes is developed. The constrained modal analysis of the chassis is carried out according to the real connection position of suspensions. Two bending modes at $28.71 \mathrm{~Hz}$ (the first-order bending mode) and $35.45 \mathrm{~Hz}$ (the second-order bending mode) are 


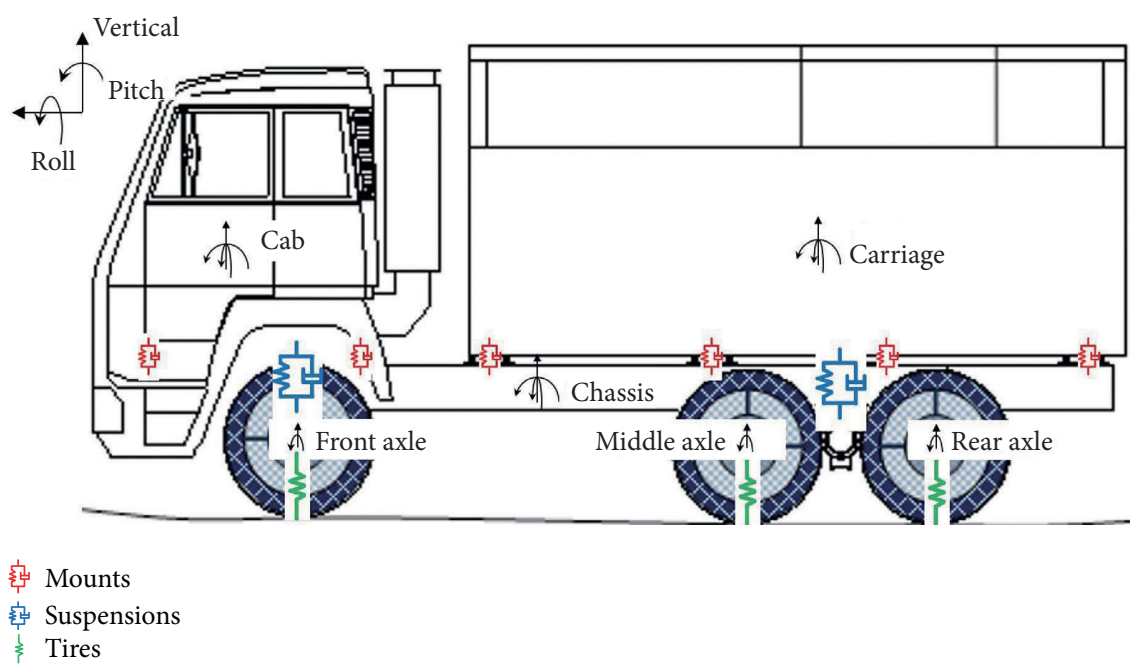

FIGURE 1: Schematic of the heavy-duty vehicle model.

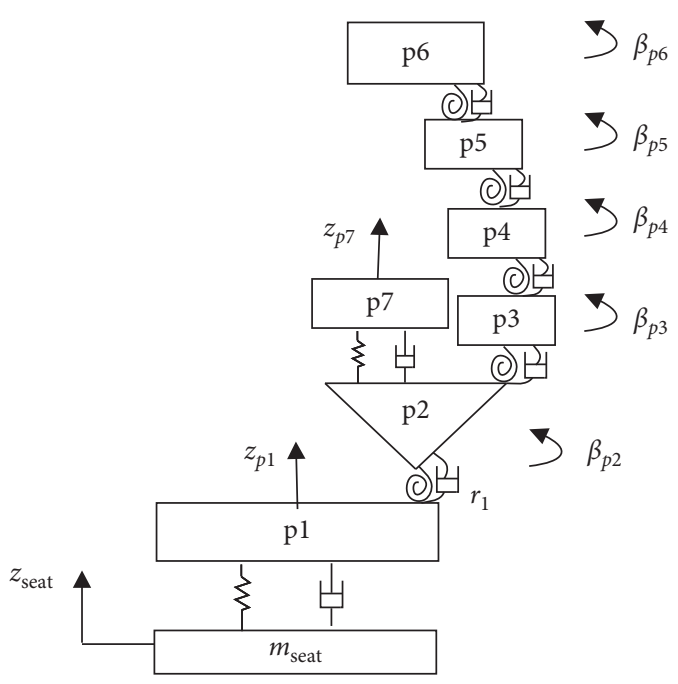

FIgUre 2: Biodynamic model of the seated human body.

found within the ride frequency, 0 to $50 \mathrm{~Hz}$. The mode shapes of the constrained chassis are given in Figure 3.

To consider the two bending modes in the vehicle model, the chassis is simplified as an elastic beam with the corresponding mode shape functions. The bending vibration of the elastic-beam chassis is

$$
\rho A \frac{\partial^{2} y}{\partial t^{2}}+E I \frac{\partial^{4} y}{\partial t^{4}}=0
$$

The $n$th mode shape function of the bending vibration is

$$
\begin{aligned}
W_{n}(x)= & \sin \beta_{n} x+\sinh \beta_{n} x \\
& +\frac{\sin \beta_{n} l-\sinh \beta_{n} l}{\cosh \beta_{n} l-\cos \beta_{n} l}\left(\cos \beta_{n} x+\cosh \beta_{n} x\right),
\end{aligned}
$$

where $\beta_{\mathrm{n}}=(n+(1 / 2))(\pi / l)$. As the external force $f\left(x_{i}\right)$ loads on $x_{i}$, a time-dependent $\Psi_{n}(t)$ differential equation can be obtained as

$$
m_{n} \ddot{\psi}_{n}(t)+2 m_{n} \zeta_{n} \omega_{n} \dot{\psi}_{n}(t)+m_{n} \omega_{n}^{2} \psi_{n}(t)=\sum_{i=1}^{k} f\left(x_{i}\right) W_{n}\left(x_{i}\right) \text {, }
$$

where $m_{n}$ is the $n$th order modal mass of the chassis, $\omega_{n}$ is the $n$th order modal frequency of the chassis, and $\xi$ is the $n$th order damping ratio of the chassis. These parameters can be obtained from the modal analysis of the chassis.

2.4. Road Excitation. The road roughness is measured on a public B-class road according to ISO 8608:1995 [25]. An eighty-meter road section (see Figure 4) is used in the simulation. The tracks are straight and zero-paddings are used to settle down the dynamic model in the early iterations.

2.5. Numerical Method. The equations of motion are solved using the Newmark- $\beta$ method, the iteration step is $0.00001 \mathrm{~s}$, and the dynamic responses are recorded accordingly.

\section{Results and Discussion}

3.1. Effects of Vibration Mode of Chassis. To investigate the effect of the vibration mode of the chassis, three vehicle models are compared, including (1) the 15-DOF model with a rigid chassis, (2) the 16-DOF model considering the first bending mode of the chassis, and (3) the 17-DOF model considering the first two bending modes of the chassis.

Taking the $60 \mathrm{~km} / \mathrm{h}$ case as an example, the vibrations of the cab and the carriage of the above three vehicle models are calculated and compared, as listed in Table 1. A common pattern is found for the vibrations of the cab and the carriage in different directions: as the number of DOFs of the model increases, the vibrations decrease except the pitch of the cab. That is to say, the calculated vibration of the uppers tends to decrease when the vibration mode of the chassis is considered. The roll vibration is the most sensitive component to the first vibration mode of the chassis among the three 

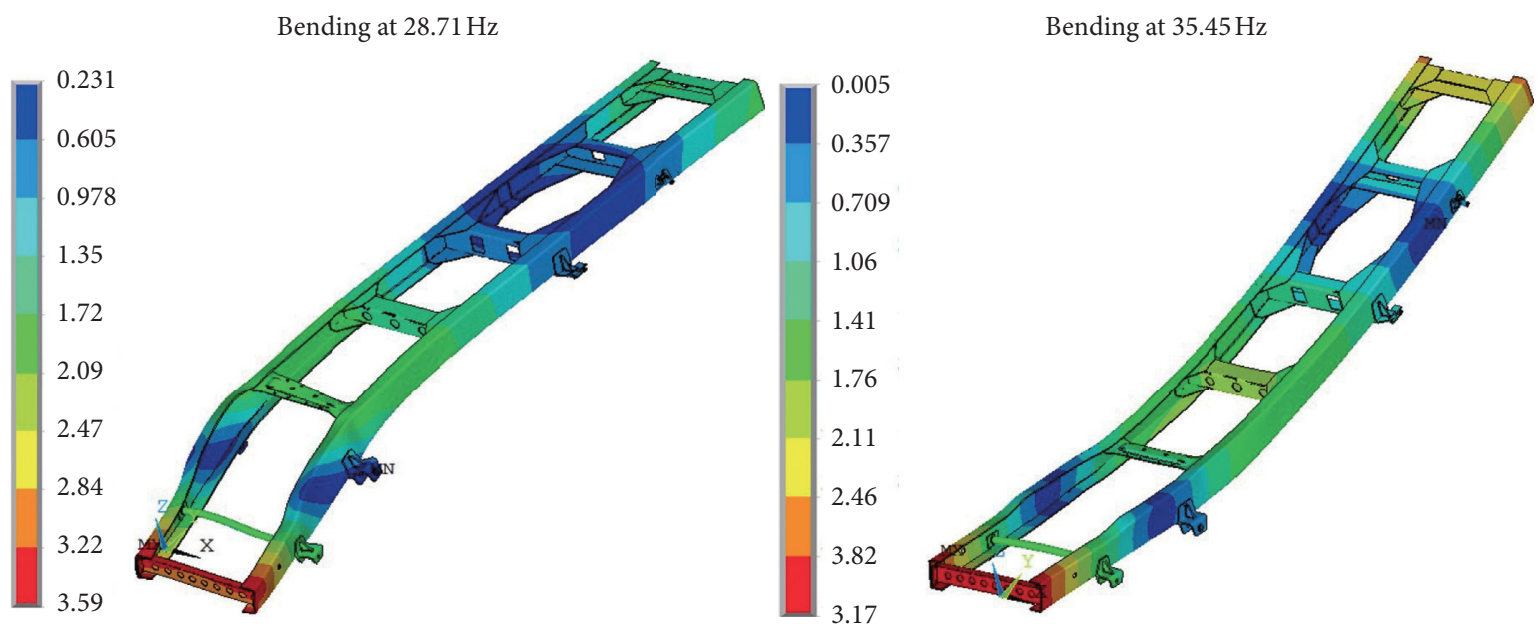

Figure 3: Mode shapes of the constrained chassis at $28.71 \mathrm{~Hz}$ and $35.45 \mathrm{~Hz}$.

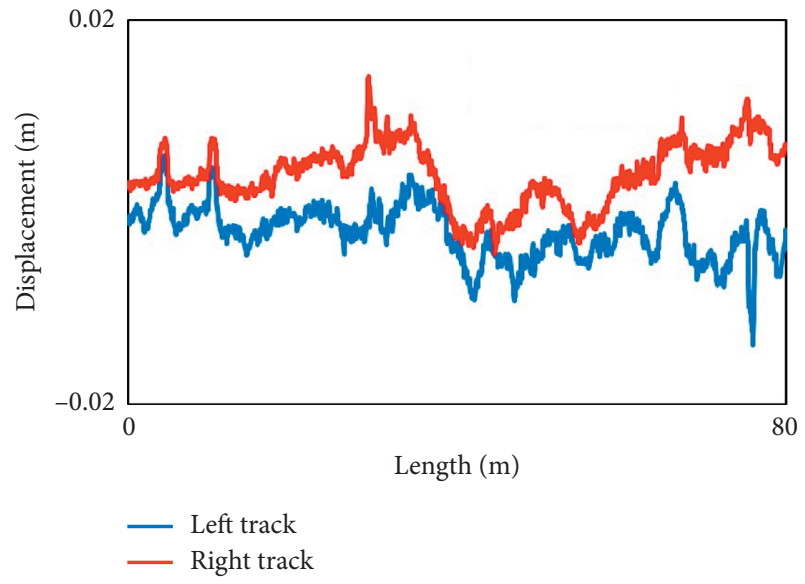

FIgURE 4: Road roughness of $80 \mathrm{~m}$ length.

TABLE 1: Comparison of vibrations r.m.s. at cab and carriage of 15-, 16- and 17-DOF models.

\begin{tabular}{lcccc}
\hline Position & Direction & 15-DOF $\left(\mathrm{m} / \mathrm{s}^{2}\right)$ & 16-DOF $\left(\mathrm{m} / \mathrm{s}^{2}\right)$ & $17-\mathrm{DOF}$ \\
\hline \multirow{4}{*}{ Cab } & Vertical & 1.05 & 0.84 & 0.75 \\
& Roll & 0.68 & 0.38 & 0.38 \\
& Pitch & 1.40 & 1.56 & 1.86 \\
\multirow{4}{*}{ Carriage } & Vertical & 1.56 & 1.40 & 1.26 \\
& Roll & 11.68 & 3.57 & 3.57 \\
& Pitch & 2.03 & 1.78 & 1.45 \\
\hline
\end{tabular}

directions. It is because the vibrations of the uppers are suppressed with the introduction of the bending mode around $28 \mathrm{~Hz}$ of the chassis.

The power spectrum densities (PSDs) of the carriage in different directions at $60 \mathrm{~km} / \mathrm{h}$ are calculated for the 15-, 16-, and 17-DOF models, as shown in Figure 5. For the vertical direction, the peak vibration energy of the carriage at $8.1 \mathrm{~Hz}$ is greatly reduced from 0.51 (15-DOF) to 0.38 (16-DOF) and 0.27 (17-DOF) by the flexibility of chassis. The second vibration peak slides from $14.7 \mathrm{~Hz}$ to $12.1 \mathrm{~Hz}$, but the amplitude remains the same. For the roll vibration, the energy concentration at $25.9 \mathrm{~Hz}$ is significantly decreased from 3.06
(15-DOF) to 0.41 (17-DOF) by $86 \%$. The second peak at $27.4 \mathrm{~Hz}$ is also suppressed from 2.23 (15-DOF) to 0.78 (17DOF), which explains why the r.m.s. acceleration in the roll direction has the most obvious reduction among the three directions. For the pitch vibration, a nearly $50 \%$ reduction in carriage is found for the first peak at $8.1 \mathrm{~Hz}$ when the bending modes of the chassis are considered.

3.2. Model Validation. The vibration acceleration of the heavy-duty vehicle is measured to conduct the model validation. The vibration at the centre of the carriage floor is measured according to ISO 2631-1 1997. In the experiment, the vehicle travels on a straight B-class road at different steady speeds of $40,50,60,70$, and $80 \mathrm{~km} / \mathrm{h}$. The vibration acceleration caused by the road roughness is recorded for $10 \mathrm{~s}$ duration. The comparisons are carried out between the measured acceleration r.m.s. at different vehicle speeds and the simulation results of 15-, 16-, and 17-DOFs models, as shown in Figure 6. Both the experiment and the simulation show a common pattern that the vehicle vibration increases obviously with increasing travel speed. For the three dynamic models, more DOFs lead to lower calculated vibration acceleration r.m.s. of the carriage and better agreement with the experimental results. Relative error between the calculated acceleration r.m.s. with 17-DOF model and the experimental results is less than $4 \%$ for all five speeds, showing the best agreement.

3.3. Sensitivity of Design Variables on Ride Vibration. An optimal Latin hypercube design is carried out using the 20 design variables including the stiffness and damping of the chassis suspensions, the seat suspension, the cab mounts, the carriage mounts, and the locations of carriage mounts. The responses are the overall weighted acceleration r.m.s. of the human body and the acceleration r.m.s. of the carriage. The response of the human body is given as follows [26]:

$$
a_{v}=\left(k_{s z}^{2} a_{s z}^{2}+k_{b z}^{2} a_{b z}^{2}+k_{b x}^{2} a_{b x}^{2}\right)^{(1 / 2)},
$$




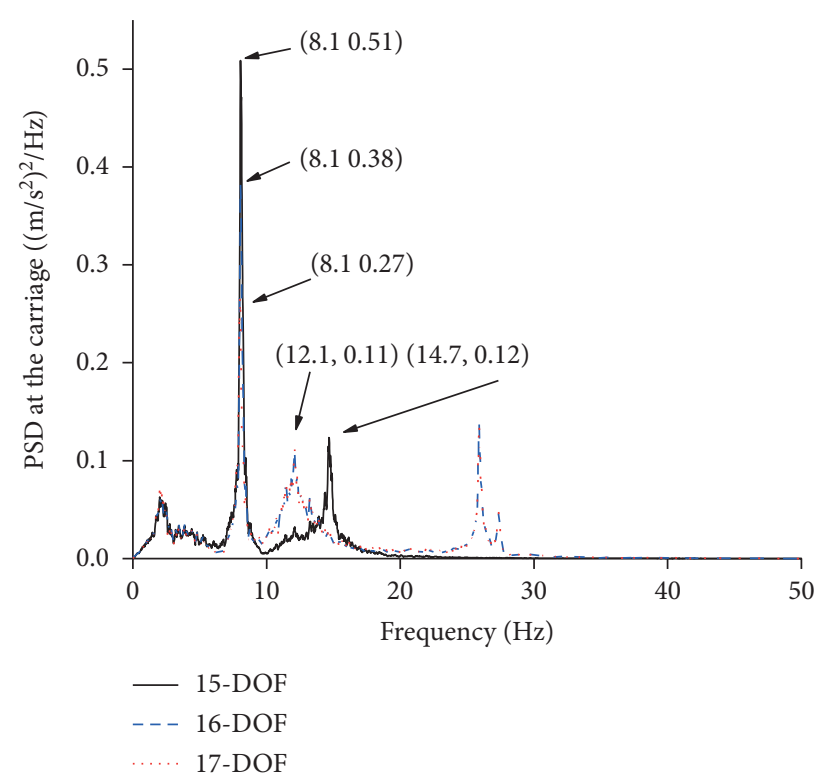

(a)

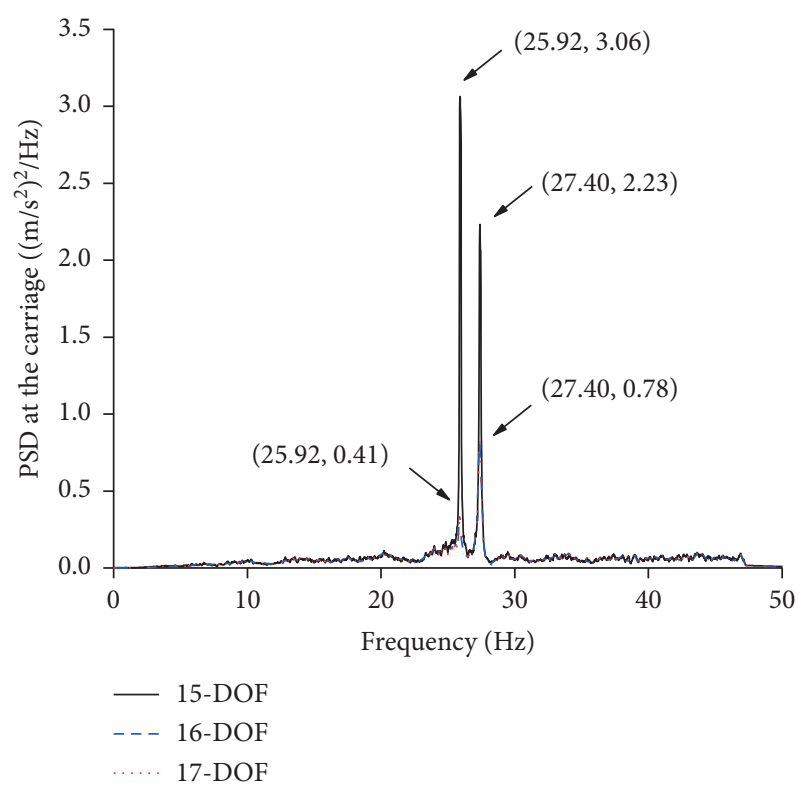

(b)

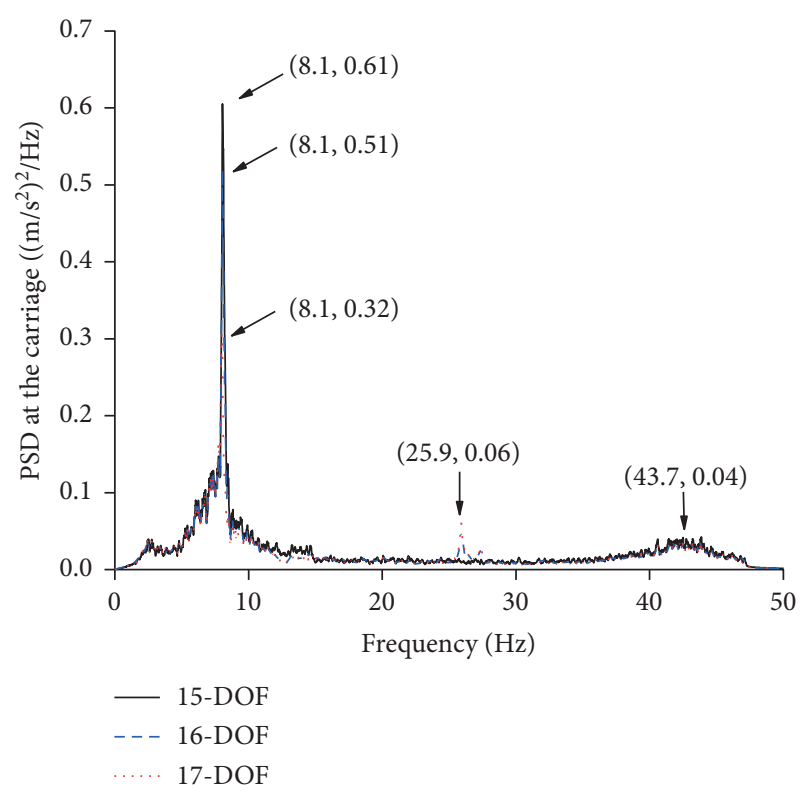

(c)

FIGURE 5: PSDs of the carriage vibration in (a) vertical, (b) roll, and (c) pitch directions.

where $a_{v}$ is the overall weighted acceleration r.m.s. of the human body, $k_{s z}$ of 1.0 and $a_{s z}$ are the weighting factor and the acceleration at the thigh in the vertical direction, $k_{b z}$ of 0.4 and $a_{b z}$ are the weighting factor and the acceleration at the back in the vertical direction, and $k_{b x}$ of 0.8 and $a_{b x}$ are the weighting factor and the acceleration at the back in the fore-and-aft direction.

The standardized effects of design variables are calculated and shown in Figure 7. The dashed line is the limit calculated according to the T-statistics. A horizontal bar exceeding the limit means the corresponding variable has statistically significant effect on the response. The blue bar means the effect of the design variable on the response is positive, while the red bar means negative effect.

It can be seen the stiffness of the seat suspension, the damping of the cab mounts, the stiffness of the front chassis suspension, the damping of the seat suspension, and the stiffness of the front cab mount affect the driver vibration significantly in descending order. The damping of the chassis suspensions, the stiffness of the rear suspension, the stiffness of the carriage mounts, and the distance between the middle mount and the centre of gravity (CG) of the carriage have significant effects on the carriage vibration. 


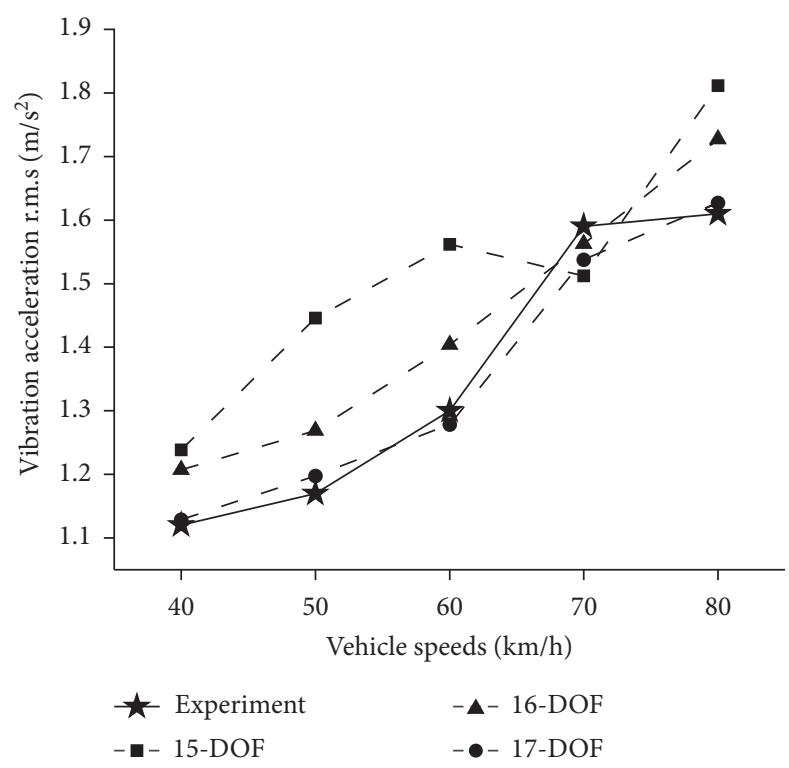

FIGURE 6: Comparisons of the vibration acceleration r.m.s. at different vehicle speeds between experimental and simulation results.

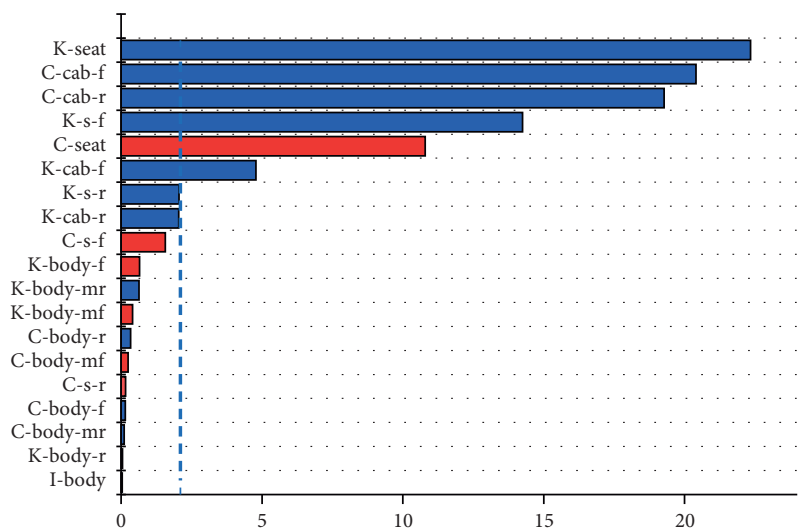

(a)

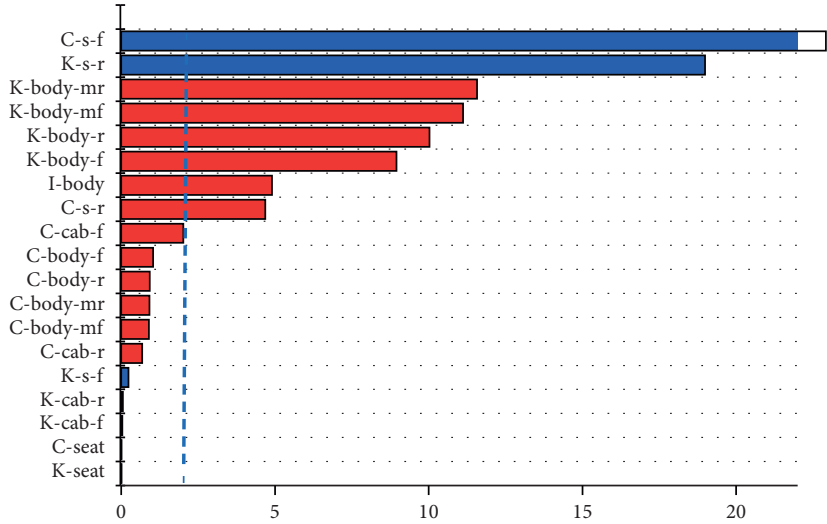

(b)

FIgURE 7: Standardized effects of design variables on the responses at (a) the human body and (b) the carriage.

3.4. Surrogate Model of Ride Analysis. In ride optimisation, a huge number of iterations will be carried out to find the best combination of design variables. Although the dynamic model is developed mathematically and the numerical solution method is quite efficient, the optimisation process is still time-consuming. So, a surrogate model is developed by the response surface method (RSM) based on the data generated by the design of experiment. The acceleration of the human body and the carriage are compared between the RSM predictions and the dynamic model, as shown in Figure $8 . R^{2}$ of the human body is 0.999 and that of the carriage is 0.993 . The biggest gap between the surrogate model and the dynamic model is less than $5 \%$, which verifies the availability of the surrogate model in optimisation.

3.5. Optimisation of Ride Vibration. The significant parameters of the model are picked as optimisation variables. To seek better balance between the ride comfort and the cargo safety, two objectives are employed: the overall weighted acceleration r.m.s. of the driver and the acceleration of the carriage. Four constrains are set corresponding to the partial frequencies of the front and the rear suspensions and the static flexibilities of the front and the rear suspensions. The optimisation problem can be described as follows:

Find: minimise $\left\{a_{\mathrm{v}}, a_{\text {carriage }}\right\}$, subject to: $0.8<f_{\mathrm{f}}<1.15 \mathrm{~Hz}$, $0.98<f_{\mathrm{r}}<1.3 \mathrm{~Hz}, 150<\delta_{\mathrm{f}}<300 \mathrm{~mm}$, and $128<\delta_{\mathrm{r}}<255 \mathrm{~mm}$.

Except for the location of the middle mount of the carriage, the range of other optimisation variables is set as $80 \%$ to $120 \%$ of the baseline value. Since the mount arrangement affects the vibration of the carriage a lot, the modal analysis of the carriage is carried out to obtain the mode shape for determination of the mounting positions. As shown in Figure 9, a vibration mode is found below $30 \mathrm{~Hz}$ falling into the ride frequency range. According to the mode shape, the distance between the middle mount and the carriage CG is set as $(1,1.5) \mathrm{m}$. 


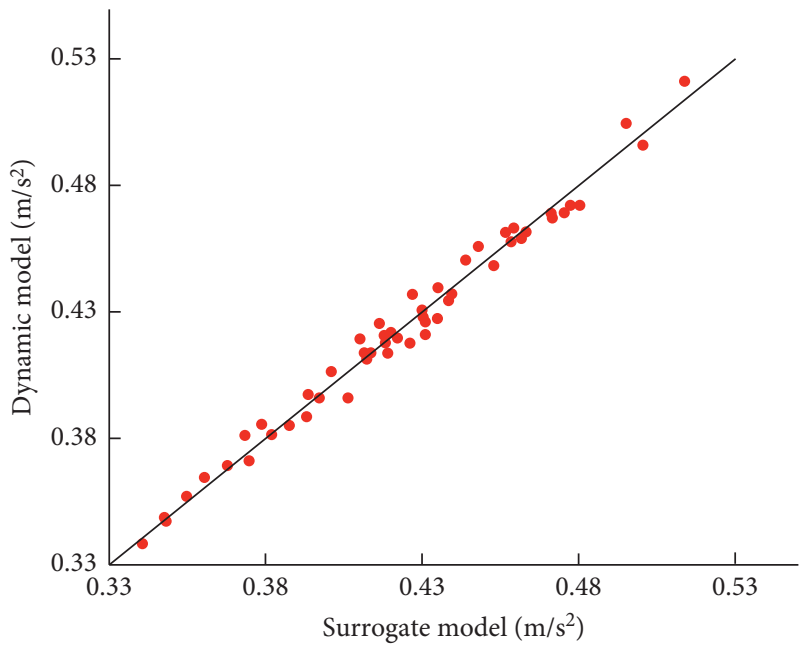

(a)

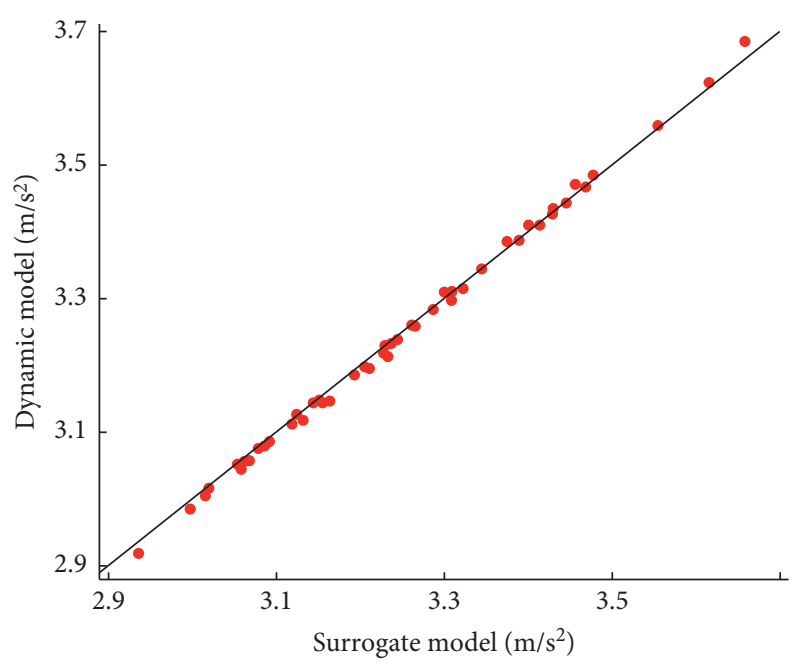

(b)

FIGURE 8: Comparisons between prediction of the RSM and calculation of the dynamic model of (a) the human body and (b) the carriage.

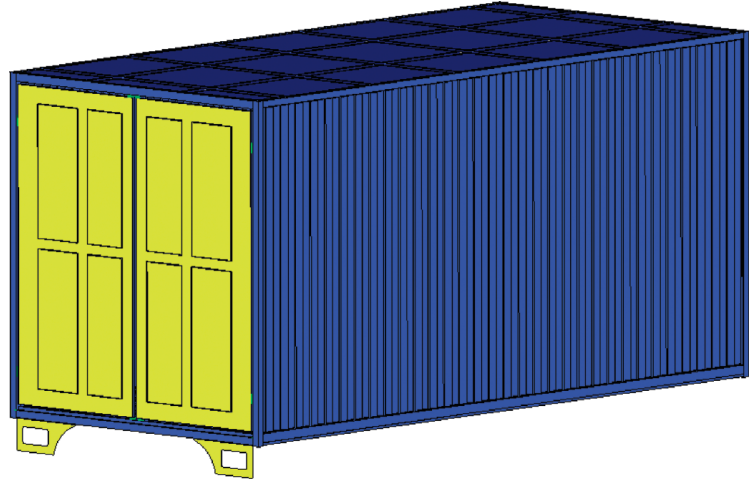

(a)

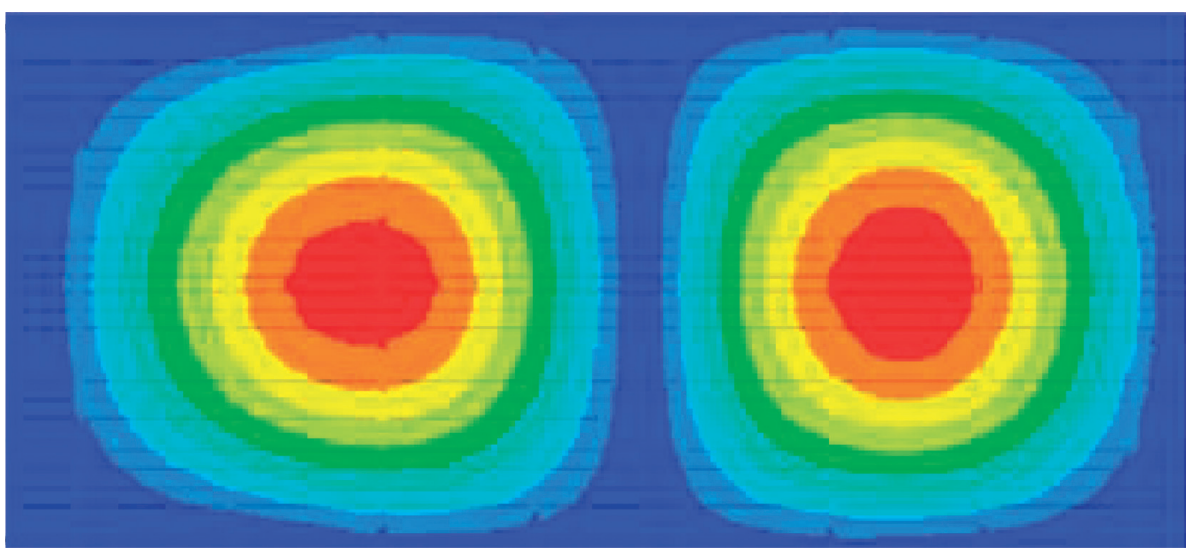

(b)

Figure 9: Modal analysis of the carriage: (a) the finite element model and (b) the mode shape below $30 \mathrm{~Hz}$.

The multiobjective optimisation is carried out by the particle swarm optimisation algorithm. The optimal design variables are listed in Table 2.

Using the optimised parameters, the vibrations of the driver and the carriage are simulated and compared to that calculated with the baseline parameters, as listed in Tables 3 and 4. It can be seen the weighted acceleration r.m.s. of the driver significantly reduces at all travel speeds from $40 \mathrm{~km} / \mathrm{h}$ to $80 \mathrm{~km} / \mathrm{h}$.

In the original condition, there is "a little uncomfortable" at all those speeds according to ISO 2631: 1-1997. After the optimisation, an average of $27.9 \%$ reduction of the weighted 
TABLE 2: Optimal results of design variables.

\begin{tabular}{lccc}
\hline Design variable & Unit & Baseline & Optimisation \\
\hline Stiffness of front suspension & $\mathrm{N} / \mathrm{m}$ & 595390 & 476312 \\
Stiffness of rear suspension & $\mathrm{N} / \mathrm{m}$ & 1552190 & 61290 \\
Damping of front suspension & $\mathrm{Ns} / \mathrm{m}$ & 5000 & 41752 \\
Damping of rear suspension & $\mathrm{Ns} / \mathrm{m}$ & $\mathrm{N} / \mathrm{m}$ & 11870 \\
Stiffness of front mount of cab & $\mathrm{N} / \mathrm{m}$ & 11870 \\
Stiffness of rear mount of cab & $\mathrm{Ns} / \mathrm{m}$ & 5290 \\
Damping of front mount of cab & $\mathrm{Ns} / \mathrm{m}$ & 5290 \\
Damping of rear mount of cab & $\mathrm{N} / \mathrm{m}$ & 20000 \\
Stiffness of seat suspension & $\mathrm{Ns} / \mathrm{m}$ & 200 & 9490 \\
Damping of seat suspension & $\mathrm{N} / \mathrm{m}$ & 4830700 \\
Stiffness of front mount of carriage & $\mathrm{N} / \mathrm{m}$ & 4830700 \\
Stiffness of front middle mount of carriage & $\mathrm{N} / \mathrm{m}$ & 4830700 \\
Stiffness of rear middle mount of carriage & $\mathrm{N} / \mathrm{m}$ & 4830700 \\
Stiffness of rear mount of carriage & $\mathrm{m}$ & 1.0 \\
Distance between middle mount and carriage CG & & 4232 \\
\hline
\end{tabular}

TABLE 3: Comparison of driver weighted acceleration r.m.s. before and after optimisation.

\begin{tabular}{lccc}
\hline Speed $(\mathrm{km} / \mathrm{h})$ & Origin $\left(\mathrm{m} / \mathrm{s}^{2}\right)$ & Optimised $\left(\mathrm{m} / \mathrm{s}^{2}\right)$ & Variation \\
\hline 40 & 0.430 & 0.296 & $-31.2 \%$ \\
50 & 0.431 & 0.298 & $-30.9 \%$ \\
60 & 0.415 & 0.312 & $-24.8 \%$ \\
70 & 0.493 & 0.368 & $-25.4 \%$ \\
80 & 0.554 & 0.404 & $-27.1 \%$ \\
\hline
\end{tabular}

TABle 4: Comparison of carriage acceleration r.m.s. before and after optimisation.

\begin{tabular}{lccc}
\hline Speed $(\mathrm{km} / \mathrm{h})$ & Origin $\left(\mathrm{m} / \mathrm{s}^{2}\right)$ & Optimised $\left(\mathrm{m} / \mathrm{s}^{2}\right)$ & Variation \\
\hline 40 & 3.459 & 2.371 & $-31.5 \%$ \\
50 & 3.922 & 2.640 & $-32.7 \%$ \\
60 & 4.012 & 2.740 & $-31.7 \%$ \\
70 & 4.713 & 3.078 & $-34.7 \%$ \\
80 & 4.654 & 3.329 & $-28.5 \%$ \\
\hline
\end{tabular}

acceleration r.m.s. of the driver is reached. From the subjective respective, the change of environmental vibration can be identified by human being if the variation is greater than $10 \%$ from the baseline. As a result, a perceptible improvement in ride comfort is achieved. The vibration reduction in all the three directions improves the ride quality to a higher level comparing with the original "little discomfort" sensation and the ride assessment becomes "no discomfort" for low speeds (i.e., $40 \mathrm{~km} / \mathrm{h}-60 \mathrm{~km} / \mathrm{h}$ ). The objective vibration at higher speeds, that is, $70 \mathrm{~km} / \mathrm{h}$ and $80 \mathrm{~km} / \mathrm{h}$, are suppressed greatly as well, but the reduction of vibration is not great enough to be perceived by the driver.

For the cargo safety, the vibration of the carriage at various speeds is reduced at the same time. In the original case, the vibration at $70 \mathrm{~km} / \mathrm{h}$ is the worst. After optimisation, the most significant vibration attenuation achieves $34.7 \%$. An average of $31.8 \%$ vibration decrease is obtained thanks to the comprehensive consideration of driver and carriage.

\section{Conclusions}

(1) A 24-DOF vertical-pitch-roll driver-vehicle coupled dynamic model is developed to describe the comprehensive ride vibration of occupant as well as carriage caused by road roughness. The flexibility of the chassis is considered at the same time. The mechanical properties of the mounts and suspensions and the arrangement of the sprung masses are optimised in order to achieve a compromise between the ride comfort and the cargo safety in multiple directions. The main conclusions are drawn as follows. The pitch motion of upper body of the driver plays an important role in the ride comfort evaluation as well as the optimisation of vehicle vibration. The developed 24-DOF driver-vehicle model can reflect the pitch and vertical vibrations of the seated driver, which provides critical information in ride assessment and optimisation.

(2) The flexibility of the chassis is vital considering the mode shapes greatly affect the dynamic responses of driver, cab, and carriage in terms of resonance peak and frequency. The flexibility of the carriage is also important for the mounting arrangement since the modal deformations constrain the mounting positions.

(3) A surrogate model is very efficient for the ride prediction of vehicle-level simulation. The sensitivity analysis shows the stiffness and damping coefficients of vehicle suspensions are the most significant factors for the vibration of cab and carriage. Among the design factors of sprung substructures, the mounting factors are more important than the upper body geometries.

(4) The optimisation of ride comfort and the cargo safety is achieved simultaneously. The weighted driver vibration reduces on average by about $27.9 \%$ and the vibration of carriage reduces by $31.8 \%$ at different speeds. 
(5) The proposed simulation approach can design the ride vibration in a driver-vehicle level in multiple directions. In further research, the response of human being to multiaxis vibration should be considered to benefit the ride comfort design.

\section{Data Availability}

The dynamic model data used to support the findings of this study are included within the article and references.

\section{Disclosure}

Peng Guo and Jiewei Lin are co-first authors.

\section{Conflicts of Interest}

The authors declare that there are no conflicts of interest regarding the publication of this paper.

\section{Authors' Contributions}

Peng Guo and Jiewei Lin contributed equally to this work.

\section{Acknowledgments}

The authors gratefully acknowledge the project supported by the National Natural Science Foundation of China (51705357) and Tianjin Natural Science Foundation (18JCQNJC05500 and 18JCYBJC20000).

\section{References}

[1] T. Yuvapriya and P. Lakshmi, "Simulation study on ride comfort enhancement for a heavy duty vehicle with fractional order sliding mode controller," SN Applied Sciences, vol. 2, no. 9, p. 1478, 2020.

[2] K. Chen, S. He, E. Xu, R. Tang, and Y. Wang, "Research on ride comfort analysis and hierarchical optimization of heavy vehicles with coupled nonlinear dynamics of suspension," Measurement, vol. 165, p. 108142, 2020.

[3] M. A. A. Abdelkareem, L. Xu, M. K. A. Ali et al., "Analysis of the prospective vibrational energy harvesting of heavy-duty truck suspensions: a simulation approach," Energy, vol. 173, pp. 332-351, 2019.

[4] M. A. Abdelkareem, M. M. Kaldas, M. Kamal Ahmed Ali, and L. Xu, "Analysis of the energy harvesting potential-based suspension for truck semi-trailer," in Proceedings of the Institution of Mechanical Engineers, Part D: Journal of Automobile Engineering, vol. 233, no. 11, pp. 2955-2969, 2018.

[5] M. A. Abdelkareem, M. M. Makrahy, A. M. Abd-El-Tawwab, A. EL-Razaz, M. Kamal Ahmed Ali, and M. Moheyeldein, "An analytical study of the performance indices of articulated truck semi-trailer during three different cases to improve the driver comfort," in Proceedings of the Institution of $\mathrm{Me}$ chanical Engineers, Part K: Journal of Multi-Body Dynamics, vol. 232, no. 1, pp. 84-102, 2017.

[6] J. P. C. Gonçalves and J. A. C. Ambrósio, "Optimization of vehicle suspension systems for improved comfort of road vehicles using flexible multibody dynamics," Nonlinear Dynamics, vol. 34, no. 1/2, pp. 113-131, 2003.
[7] D. Anderson, "Development of a multi-body dynamic model of a tractor-semitrailer for ride quality prediction," $S A E$ Transactions, vol. 110, pp. 351-362, 2001.

[8] J. C. Gonçalves and J. C. Ambrósio, "Road vehicle modeling requirements for optimization of ride and handling," Multibody System Dynamics, vol. 13, no. 1, pp. 3-23, 2005.

[9] J. Zhou, R. Goodall, L. Ren, and H. Zhang, "Influences of car body vertical flexibility on ride quality of passenger railway vehicles," in Proceedings of the Institution of Mechanical Engineers, Part F: Journal of Rail and Rapid Transit, vol. 223, no. 5, pp. 461-471, 2009.

[10] I. M. Ibrahim, Non-Linear Simulation Model for Articulated Vehicles with Controllable Dampers and Flexible Sub-structures, SAE International, Warrendale, PA, USA, 2002.

[11] B. Tan, "A condensed dynamic model of a heavy-duty truck for optimization of the powertrain mounting system considering the chassis frame flexibility," in Proceedings of the Institution of Mechanical Engineers, Part D: Journal of Automobile Engineering, vol. 234, no. 10-11, pp. 2602-2617, 2020.

[12] A. Gupta and V. Rastogi, "Effect of distributed damping on the dynamic behavior of flexible chassis of heavy road vehicle under standardized random road responses," Iranian Journal of Science and Technology, Transactions of Mechanical Engineering, 2020.

[13] D. Ning, S. Sun, H. Du, W. Li, and W. Li, "Control of a multiple-DOF vehicle seat suspension with roll and vertical vibration," Journal of Sound and Vibration, vol. 435, pp. 170-191, 2018.

[14] J. Lin, Z. Lin, L. Ma, T. Xu, D. Chen, and J. Zhang, "Analysis and optimization of coupled vibration between substructures of a multi-axle vehicle," Journal of Vibration and Control, vol. 25, no. 5, pp. 1031-1043, 2019.

[15] D. Ning, "Control of a multiple-DOF vehicle seat suspension with roll and vertical vibration," Journal of Sound and Vibration, 2018.

[16] X. Zheng, Z. Hao, X. Wang, and J. Mao, “A full-spectrum analysis of high-speed train interior noise under multiphysical-field coupling excitations," Mechanical Systems and Signal Processing, vol. 75, pp. 525-543, 2016.

[17] J. J. Arnold and M. J. Griffin, "Equivalent comfort contours for fore-and-aft, lateral, and vertical whole-body vibration in the frequency range 1.0 to $10 \mathrm{~Hz}$," Ergonomics, vol. 61, no. 11, pp. 1545-1559, 2018.

[18] Y. Huang and P. Zhang, "Subjective discomfort caused by vertical whole-body vibration in the frequency range 2-100 Hz," Ergonomics, vol. 62, no. 3, pp. 420-430, 2019.

[19] L. Zhao, C. Zhou, and Y. Yu, "Damping collaborative optimization of five-suspensions for driver-seat-cab coupled system," Chinese Journal of Mechanical Engineering, vol. 29, no. 4, pp. 773-780, 2016.

[20] L. Zhao, C. Zhou, Y. Yu, and F. Yang, "An analytical formula of driver RMS acceleration response for quarter-car considering cushion effects," Vehicle System Dynamics, vol. 55, no. 9, pp. 1283-1296, 2017.

[21] G. Wang, J. Zhang, and X. Kong, "Study on passenger comfort based on human-bus-road coupled vibration," Applied Sciences, vol. 10, no. 9, p. 3254, 2020.

[22] K. C. Parsons and M. J. Griffin, "Vibration and comfort II. Rotational seat vibration," Ergonomics, vol. 25, no. 7, pp. 631-644, 1982.

[23] Z. Lin, "Biodynamic response of seated human body to roll vibration and correlation between roll and lateral directions," Shock and Vibration, vol. 2020, p. 8839363, 2020. 
[24] M. Yang, "Effects of sitting posture and seat backrest on the biodynamic response of the human body and prediction of spinal forces during vertical whole-body vibration," in Institute of Sound and Vibration Research, Faculty of Engineering and the EnvironmentUniversity of Southampton, Southampton, UK, 2016.

[25] I. Standard, Mechanical Vibration-Road Surface ProfilesReporting of Measured Data, 1995.

[26] ISO, Mechanical Vibration and Shock: Evaluation of Human Exposure to Whole-Body Vibration. Part 1, General Requirements, ISO, London, UK, 1997. 